\title{
УДК: 346.1
}

\section{Соловяненко Нина Ивановна}

кандидат юридических наук,

старший научный сотрудник Сектора предпринимательского и корпоративного права,

Институт государства и права РАН

spp@igpran.ru

\section{Nina I. Solovyanenko}

$\mathrm{PhD}$ in law

Senior Research Fellow of Business and Corporate Law Department, Institute of State and Law of RAS

spp@igpran.ru

\section{ЮРИДИЧЕСКИЕ СТРАТЕГИИ ЦИФРОВОЙ ТРАНСФОРМАЦИИ АГРАРНОГО БИЗНЕСА}

\section{LEGAL STRATEGIES FOR DIGITAL TRANSFORMATION OF AGRICULTURAL BUSINESS}

Аннотация. Развитие мирового агропромышленного производства и торговли продовольствием в последние десятилетия подразумевает цифрровую трансформацию и переход на новый технологический уклад, что является существенным фактором устойчивого развития. Цифровизация сельского хозяйства и продовольственного сектора осуществляется на основе IT-платформ, Интернета вещей, облачных вычислений, больших данных, искусственного интеллекта, блокчейн технологии. Фрагментарные и неясные правовые конструкиии, медленное обновление правового регулирования сдерживают внедрение циирровых решений. Основанная на цифровых стратегиях современная нормативная база должна укрепить доверие аграриев к «умному сельскому хозяйству». В России правовой механизм стратегического планирования охватывает развитие национальной платформы «Цифровое сельское хозяйство». Цифровые стратегии также включают обновление базового законодательства.

Ключевые слова: устойчивое развитие, продовольственная безопасность, иирровые стратегии, «умное сельское хозяйство», национальная платформа «иифровое сельское хозяйство», правовое регулирование циифровизачии сельского хозяйства, информационное обеспечение в сфере сельского хозяйства.

Abstract.The development of global agricultural production and food trade in recent decades implies a digital transformation and the transition to a new technological order, which is an essential factor for sustainable development. Digitalization of agriculture and the food sector is carried out on the basis of IT 
platforms, the Internet of Things, cloud computing, big data, artificial intelligence, and blockchain technology. Fragmented and unclear legal mechanisms, slow updating of legal regulation hinder the introduction of digital solutions. A modern regulatory framework based on digital strategies should strengthen the confidence of farmers in "smart agriculture". In Russia, the legal mechanism of strategic planning covers the development of the national platform "Digital Agriculture". Digital strategies also include updating basic legislation.

Keywords: sustainable development, food security, digital strategies, "smart agriculture", national platform "digital agriculture", legal regulation of digitalization of agriculture, information support in the field of agriculture.

Мировое агропромышленное производство и торговля продовольствием значительно изменились за последние два десятилетия. Цифровая трансформация и переход на новый технологический уклад открывают небывалые возможности для реализации целей и задач Повестки дня ООН в области устойчивого развития на период до 2030 года, которые включают «поддержание продовольственной безопасности; развитие сельских районов и внедрение устойчивых методов ведения сельского и рыбного хозяйства; сохранение и рациональное использование природных ресурсов планеты»[6, с.94-102; 7, с. 81-90].

Цифровизация процессов в сельском хозяйстве и продовольственном секторе осуществляется на основе многочисленных технологических решений: электронный обмен данными (EDI); IT-платформы, датчики и Интернет вещей (IоT); облачные вычисления, большие данные, искусственный интеллект и технологии распределенных реестров, такие как блокчейн. Эти технологии находятся на разных стадиях развития; EDI используется с 1990-х годов, а блокчейн-технологии и искусственный интеллект в сельском хозяйстве и пищевой промышленности все еще разрабатываются.

Суть цифровой трансформации заключается в производстве, передаче и анализе данных способами, которые ранее были технологически или финансово невозможны. Цифровые технологии позволяют собирать, фиксировать и обрабатывать большой объем данных в области агропромышленного производства, например, необработанные данные, полученные от удаленных систем, таких как спутники, а также агрегированные и обработанные данные, полученные в результате обследований и переписей. Сельскохозяйственные данные анализируются производителями в целях более точного использования сельскохозяйственных ресурсов; адаптации к погодным и климатическим условиям; автоматизации повторяющихся задач; а также более эффективного ведения учета и администрирования. Доступ к сельскохозяйственным данным, обмен ими и их использование для более эффективного принятия решений и внедрения инноваций лежат в основе цифрового сельского хозяйства. «Цифровая революция" в сельском 
хозяйстве дает возможность подключить все производственные процессы к одной большой платформе, позволяющей собирать, систематизировать и обмениваться информацией с ферм и полей в онлайн-режиме и корректировать работы на производственных участках в зависимости от полученной информации» [4]. Наращивание возможности обмена сельскохозяйственными данными также может повысить прослеживаемость сельскохозяйственной продукции. Цифровизация изменяет все звенья агропродовольственной цепочки. Управление ресурсами во всей системе становится высоко оптимизированным, индивидуализированным, интеллектуальным и упреждающим.

Однако политический, экономический, а также юридический ландшафт, в котором осуществляется цифровизация агропромышленного предпринимательства и торговли продовольствием, характеризуется не только достижениями, но также специфическим проблемами и рисками. Европейские исследования показывают нарастающую зависимость экономики от инфраструктуры и услуг информационно-коммуникационных технологий, усугубленную пандемией COVID-19. Сельское хозяйство во время пандемии стало более цифровым и вместе с тем был выявлен ряд экономических, юридических и социальных проблем, связанных с наличием, качеством и доступностью сельскохозяйственных данных, характеризующих конкретные местности и условия, а также поиском баланса между защитой частной жизни и конфиденциальности сельскохозяйственных данных и экономическими интересами фермеров. Большая часть сельскохозяйственных данных собирается на фермах, но обрабатывается с помощью программного обеспечения, права на которое принадлежат сторонним частным лицам, что вызывает принципиальный юридический вопрос: каким образом осуществляется управление этими данными - то есть, кто контролирует их и вправе извлекать из них ценность. Производители выражают обеспокоенность тем, что ненадлежащее использование полученных от фермерских хозяйств данных и обмен ими способны привести к недобросовестной конкуренции или раскрытию конфиденциальной информации о фермерских хозяйствах, что может повлиять, например, на стоимость участков земли.

Для решения вопросов управления данными используются подробные и сложные контракты, регулирующие отношения между фермерами и поставщиками техники и услуг, которые потенциально заинтересованы в сельскохозяйственных данных, генерируемых на фермах. При заключении контрактов с такими поставщиками фермеры могут находиться в неравноправном положении, обусловленном отсутствием у них необходимой информации или технической грамотности (например, терминология, используемая в контрактах, может быть предельно технологической и малопонятной для мелких производителей) $[11 ; 12]$.

Хотя контракты варьируются от компании к компании, они обычно включают условия, которые устанавливают, что можно и что нельзя делать 
с технологией и с данными, собранными посредством этой технологии. Условия использования технологии в договорах, как правило, охватывают широкий круг вопросов, таких как: кто является обладателем данных; какие данные могут передаваться; где осуществляется хранение данных (в том числе в какой стране); как обеспечивается безопасность и конфиденциальность данных; что происходит с данными, когда контракт заканчивается (устаревшими данными); что происходит с данными, когда бизнес продается или закрывается; могут ли данные быть перенесены от одного поставщика к другому; в какой стране может быть рассмотрен спор по контракту. Контракты также часто связаны с другими документами, такими как политика конфиденциальности. В некоторых случаях именно политика конфиденциальности, а не условия контракта, определяет, кто может иметь доступ к данным, генерируемым в соответствии с контрактом. Если условия, регулирующие безопасность и защиту данных, не ясны фермерам, это становится особой проблемой [13].

«Локдаун», вызванный пандемией, также продемонстрировал, что сельские жители, которые не пользуются компьютерными сетями, «не обладающие достаточными компетенциями переквалифицироваться, недостаточно мобильные по сравнению с горожанами», стали еще более изолированными и получают меньше поддержки и возможностей [9] .

Фрагментарные и неясные правовые механизмы сдерживают готовность фермеров применять цифровые решения. Например, им могут быть недоступны средства защиты прав физических лиц в отношении персональных данных, такие как контроль и ряд других, поскольку сельскохозяйственные данные не всегда подпадают под определение персональных данных. Совершенствование правового регулирования происходит медленнее, чем разработка и внедрение высоких технологий. Как справедливо указывают ученые-юристы «...действительность вводит в оборот новые феномены, новые способы экономического взаимодействия. ....к ним часто сложно подойти со старыми регуляторными подходами» [1, c.39-47]. «Проблемы и риски должны быть оценены специалистами, найдены пути их минимизации, что, в свою очередь, должно быть закреплено в законодательстве» [5, с 534-538]. В этой связи необходимо оперативное создание новейшей нормативной базы, которая укрепит доверие заинтересованных участников, инвестирующих в «умное сельское хозяйство» и использующих его потенциал для роста и инноваций данного сектора. «Новизна состоит не в изменении сути права, его природы, а в обогащении его содержания, связанного с принципиальной новизной самого средства передачи информации» [2, с.9]. Обеспечение доверия как одну из фундаментальных задач правового регулирования цифровой экономики отмечают как российские, так и зарубежные исследователи: Основная проблема, конечно, это доверие. Формально в нем заинтересованы вообще все участники новых отношений»[1, с. 39-47;8]. Следует разработать юридический механизм, способствующий преодолению «цифрового 
неравенства» в сельских районах. В Дорожной карте по цифровому сотрудничеству, представленной Генеральным секретарем $\mathrm{OOH}$, указывается, что следует объединять, уважать и защищать людей в цифровую эпоху. Люди, работающие в сельском, лесном и рыбном хозяйстве, живущие в отдаленных и сельских районах, не должны оставаться позади [9, с.vii].

Цифровые стратегии, планы и дорожные карты формируют цели и задачи правового регулирования. Так, разрабатываемые в рамках организаций экономической интеграции и отдельных государств стратегии цифрового, сельского хозяйства подразумевают создание сбалансированной системы управления цифровизацией и принятие соответствующих нормативных правовых актов в данной сфере. Создание национальной стратегии электронного сельского хозяйства является важной инициативой для любой страны, планирующей использовать информационнокоммуникационные технологии (ИКТ) в сельском хозяйстве. Любая эффективная дорожная карта для электронного сельского хозяйства потребует целостного, многостороннего подхода, поскольку ИКТ также стимулируют развитие других секторов, имеющих решающее значение для сельского хозяйства, а именно банковское дело, мониторинг погоды, землепользование, страхование, логистику и электронное государственное управление.

В Европейском Союзе Цифровая повестка дня для Европы (DAE) определяет ключевую стимулирующую роль, которую использование цифровых технологий должно сыграть в достижении Европейским Союзом амбициозных целей экономического лидерства. Чтобы обеспечить справедливую, открытую и безопасную цифровую среду, Европейская Комиссия приняла Стратегию цифрового единого рынка, в основе которой лежат следующие основные принципы: обеспечение лучшего доступа потребителей и предприятий к цифровым товарам и услугам по всей Европе, создание надлежащих условий для развития цифровых сетей и услуг и максимизация потенциала роста цифровой экономики. Стратегия цифрового единого рынка определяет основные экономические, политические и юридические условия электронного сельского хозяйства в EC.

В Европейском Союзе значительные инвестиции были направлены на продвижение крупномасштабных пилотных проектов, включая создание сельскохозяйственных цифровых платформ, поддерживающих инновации в сельскохозяйственном секторе. В частности, три пилотных проекта и одна сеть центров цифровых инноваций получили в общей сложности 80 миллионов евро на исследования и инновации в области внедрения цифровых технологий для сельскохозяйственного сектора: IoF2020, DEMETER, ATLAS и SmartAgriHubs. IoF2020, объединяющий две экосистемы - агробизнес и передовых поставщиков ИКТ, сосредоточен на содействии внедрению Интернета вещей (IoT) в пищевой промышленности 
и сельском хозяйстве. IoF2020 (Internet of Food \& Farm 2020) - фермерский проект, ориентированный на использование в двадцати двух государствахчленах ЕС, охватывает пять различных сельскохозяйственных секторов: пахотный, молочный, фруктовый, овощной и мясной. Сосредоточен на расширении использования по всей Европе, а также совершенствовании приложений и внедрении новых технологий. ATLAS (Agricultural inTeroperabiLity \& Analysis System) разрабатывает открытую цифровую сервисную платформу для сельскохозяйственных приложений, а также создает устойчивую экосистему для инновационного сельского хозяйства, основанного на данных. Проект DEMETER ориентирован на внедрение новых возможностей для бизнеса в агропродовольственную экономику и сохранение при этом природных ресурсов Европы. Проект демонстрирует, как комплексный подход к бизнес-моделированию может поддержать устойчивое сельское хозяйство и системы производства продовольствия, обеспечить людей безопасными продуктами питания и поддержать фермеров в процессе принятия ими решений [10].

В Российской Федерации концептуальные подходы к созданию национальной стратегии электронного (цифрового) сельского хозяйства, включая систему его нормативного регулирования, базируются на положениях национальной программы «Цифровая экономика РФ», а также «Доктрины продовольственной безопасности РФ», утвержденной Указом Президента РФ от 21 января 2020 г. N 20. Задача продвижения высоких технологий и развертывания цифровых платформенных решений в целях инновационного преобразования агропромышленного комплекса как одной из приоритетных отраслей российской экономики поставлена в соответствии с Указом Президента РФ от 7 мая 2018 г. № 204 «О национальных целях и стратегических задачах развития Российской Федерации на период до 2024 года».

Развитие электронного (цифрового) сельского хозяйства интегрировано в правовой механизм стратегического планирования. «Цифровое сельское хозяйство» обозначено в таком документе стратегического планирования как «Государственная программа развития сельского хозяйства и регулирования рынков сельскохозяйственной продукции, сырья и продовольствия». Постановлением Правительства РФ от 31 марта 2020 г. N 375 в данную государственную программу внесены изменения: ведомственный проект «Цифровое сельское хозяйство» включен в направление (подпрограмму) «Обеспечение условий развития агропромышленного комплекса». Проектом «Цифровое сельское хозяйство» предусмотрено применения в производстве сельскохозяйственной продукции и продовольствия высоких технологий (интернета вещей, робототехники, искусственного интеллекта, анализа больших данных, электронной коммерции, создания информационной системы сбора отраслевых данных «Единое окно» и другие). К базовым элементам проекта «Цифровое сельское хозяйство» относятся: 
«Центральная информационно - аналитическая система сельского хозяйства - банк информации, интегрированный с информационными системами Минсельхоза России, Росстата, Федеральной таможенной службы, Росгидромета, для оперативного мониторинга состояния и развития объектов аграрно-промышленного комплекса;

Единая федеральная информационная система земель сельскохозяйственного назначения, содержащая актуальную информацию о землях сельскохозяйственного назначения, интегрированную с базами Росреестра и Роскосмоса;

интеллектуальная система мер государственной поддержки и личный кабинет получателя субсидии (включая электронную идентификацию фермеров в Единой системе идентификации и аутентификации (ЕСИА) и в Единой биометрической системе;

применение правовой конструкции смарт-контракта;

«Эффективный гектар», который позволит моделировать экспортные потоки сельскохозяйственного сырья в реальном времени, предполагает точный прогноз урожаев и сроков уборки;

электронный документооборот;

масштабирование отечественных цифровых решений для предприятий АПК, таких как: «Умная ферма» «Умное поле» и ряд других;

электронная образовательная система «Земля знаний» [3].

Для проведения в жизнь цифровизации сельского хозяйства в соответствии с приказом Министерства сельского хозяйства РФ от 25 февраля 2020 г. N 84 предусмотрено создание национальной платформы «Цифровое сельское хозяйство».

Создание и ввод в эксплуатацию государственных информационных систем, входящих в состав Платформы, осуществляется в соответствии с постановлением Правительства РФ от 24.05.2010 N 365 "О координации мероприятий по использованию информационно-коммуникационных технологий в деятельности государственных органов", а также постановлением Правительства РФ от 07.03.2008 N 157 "О создании системы государственного информационного обеспечения в сфере сельского хозяйства". Государственная информационная система сбора и анализа отраслевых данных "Единое окно" проектируется в качестве источника входных данных для национальной платформы «Цифровое сельское хозяйство».

«На Форуме ProAgroTalk 1.0: «Новый технологический уклад в сельском хозяйстве. Опыт Италии и России» отмечалось, что «эффективное цифровое сельскохозяйственное производство уже внедряется в пилотных регионах. Программа объединяет высокотехнологичные международные компетенции в области образования, применения беспилотников и наноспутников, цифровых платформ для сбора, хранения, обработки данных и управления задачами» [4]. 
Правовое регулирование мероприятий, обеспечивающих цифровую трансформацию в том числе сельского хозяйства, должны поддерживаться актуализированными законодательными положениями общего характера. Так, например, ГК РФ дополнен статьей 783.1, в которой зафиксированы характерные черты договора об оказании услуг по предоставлению информации. В статье 160 ГК РФ указано, что письменная форма сделки считается соблюденной также в случае совершения лицом сделки с помощью электронных либо иных технических средств, позволяющих воспроизвести на материальном носителе в неизменном виде содержание сделки, при этом требование о наличии подписи считается выполненным, если использован любой способ, позволяющий достоверно определить лицо, выразившее волю. Статья 309 ГК РФ дополнена частью второй, в которой установлено, что: «условиями сделки может быть предусмотрено исполнение сторонами возникающих из нее обязательств при наступлении определенных обстоятельств ....путем применения информационных технологий, определенных условиями сделки». В обновленном федеральном законе «Об электронной подписи» модифицирована система удостоверяющих центров; определено понятие и разработан механизм использования метки доверенного времени; предусмотрена возможность использования «облачной» электронной подписи; введена правовая конструкция доверенной третьей стороны для внутреннего и трансграничного взаимодействия.

\section{Лuтература}

1. Габов А.В Изменения в праве как следствие развития иифровой экономики//Пермский юридический альманах. 2020. № 3. С. 39-47.

2. Зорькин В.Д. Providentia или о праве будущего в эпоху ифровизащии // Государство и право. 2020. № $6 . \quad$ C. $7-19$. DOI: 10.31857/S013207690009932-7.

3. Министерство сельского хозяйства Российской Федерации Ведомственный проект «Цифровое сельское хозяйство». URL: https ://www.mcxac.ru/ /upload/medialibrary/04c/ 104cf3968669675d0b9ecc106ad04a1a7.pdf.

4. Переход сельхозпроизводства на иифровые технологии обсудили на бизнес-форуме специалисты России и Италии = Российская газета (rg.ru) 19.02.2021.

5. Попова О.В. Цифровая деревня. $B$ книге: Материаль международной научно-практической конференции "Современные тенденции развития экологического, земельного и аграрного права". Ответственные редакторы: В.В. Устюкова, Т.В. Редникова, О.А. Самончик, Ю.А. Каспрова. 2018. С. 534-538.

6. Устюкова В.В., Биткова Л.А. Риски и угрозы продовольственной безопасности и правовые средства их преодоления//Аграрное и земельное право. 2018. № 5 (161). C. 94-102. 
7. Anisimov A., Popova O., Ustyukova V. Current Challenges of Sustainable Rural Development in Russia: Trends and Prospectives //Problemy Ekorozwoju. 2019. T. 14. № 2. C. 81-90.

8. Digital Regulation Handbook: Geneva: International Telecommunication Union and the World Bank, 2020. Licence: CC BY-NC-SA 3.0 IGO.

9. ITU and FAO. 2020. Status of Digital Agriculture in 18 countries of Europe and Central Asia. Geneva, Switzerland.

10. Large-scale pilots in the digitisation of agriculture |Shaping Europe's digital future (europa.eu).

11. Maru, A. et al. (2018), Digital and data-driven agriculture: Harnessing the power of data for smallholders, https://cgspace.cgiar.org/handle/10568/92477.

12. OECD FOOD, AGRICULTURE AND FISHERIES PAPERS $N^{\circ} 146$ ○ OECD 2020. OECD iLibrary | Issues around data governance in the digital transformation of agriculture: The farmers' perspective (oecd-ilibrary.org).

13. Wiseman, L. et al. (2019), "Farmers and their data: An examination of farmers' reluctance to share their data through the lens of the laws impacting smart farming", NJAS - Wageningen Journal of Life Sciences, Vol. 9091/December, https://doi.org/10.1016/j.njas.2019.04.007

\section{References}

1. Gabov A. V. Changes in law as a consequence of the development of the digital economy//Perm legal almanac. 2020. No. 3. Pp. 39-47.

2. Zorkin V. D. Providentia or on the law of the future in the era of digitalization. 2020. No. 6. pp. 7-19.

3. Ministry of Agriculture of the Russian Federation Departmental project "Digital Agriculture".

4. The transition of agricultural production to digital technologies was discussed at the business forum by experts from Russia and Italy Rossiyskaya Gazeta (rg.ru) 19.02.2021.

5. Popova O. V. Digital village. In the book: Materials of the international scientific and practical conference "Modern trends in the development of environmental, land and agricultural law". Responsible editors: V. V. Ustyugova, T. V. Rednikova, O. A. Samonchik, Yu.A. Kasprova. 2018. pp. 534-538.

6. Ustyukova V. V., Bitkova L. A. Risks and threats to food security and legal means to overcome them//Agrarian and land law. 2018. No. 5 (161). pp. 94-102.

7. Anisimov A., Popova O., Ustyukova V. Current Challenges of Sustainable Rural Development in Russia: Trends and Prospectives //Problemy Ekorozwoju. 2019. T. 14. № 2. C. 81-90.

8. Digital Regulation Handbook: Geneva: International Telecommunication Union and the World Bank, 2020. Licence: CC BY-NCSA 3.0 IGO. 
9. ITU and FAO. 2020. Status of Digital Agriculture in 18 countries of Europe and Central Asia. Geneva, Switzerland.

10. Large-scale pilots in the digitisation of agriculture | Shaping Europe's digital future (europa.eu).

11. Maru, A. et al. (2018), Digital and data-driven agriculture: Harnessing the power of data for smallholders, https://cgspace.cgiar.org/handle/10568/92477.

12. OECD FOOD, AGRICULTURE AND FISHERIES PAPERS $N^{\circ} 146$ (C) OECD 2020. OECD iLibrary | Issues around data governance in the digital transformation of agriculture: The farmers' perspective (oecdilibrary.org).

13. Wiseman, L. et al. (2019), "Farmers and their data: An examination of farmers' reluctance to share their data through the lens of the laws impacting smart farming”, NJAS - Wageningen Journal of Life Sciences, Vol. 90-91/December, https://doi.org/10.1016/j.njas.2019.04.007 